\title{
A case report of prostate cancer metastasis to the stomach resembling undifferentiated-type early gastric cancer
}

\author{
Chiaki Inagaki ${ }^{1,3^{*}} \mathbb{D}$, Takuto Suzuki ${ }^{1}$, Yoshiyasu Kitagawa ${ }^{1}$, Taro Hara ${ }^{1,2}$ and Taketo Yamaguchi ${ }^{2}$
}

\begin{abstract}
Background: Occurrence of metastatic cancer to the stomach is rare, particularly in patients with prostate cancer. Gastric metastasis generally presents as a solitary and submucosal lesion with a central depression.

Case presentation: We describe a case of gastric metastasis arising from prostate cancer, which is almost indistinguishable from the undifferentiated-type gastric cancer. A definitive diagnosis was not made until endoscopic resection. On performing both conventional and magnifying endoscopies, the lesion appeared to be slightly depressed and discolored area and it could not be distinguished from undifferentiated early gastric cancer. Biopsy from the lesion was negative for immunohistochemical staining of prostate-specific antigen, a sensitive and specific marker for prostate cancer. Thus, false initial diagnosis of an early primary gastric cancer was made and endoscopic submucosal dissection was performed. Pathological findings from the resected specimen aroused suspicion of a metastatic lesion. Consequently, immunostaining was performed. The lesion was positive for prostate-specific acid phosphatase and negative for prostate-specific antigen, cytokeratin 7, and cytokeratin 20. Accordingly, the final diagnosis was a metastatic gastric lesion originating from prostate cancer.
\end{abstract}

Conclusion: In this patient, the definitive diagnosis as a metastatic lesion was difficult due to its unusual endoscopic appearance and the negative stain for prostate-specific antigen. We postulate that both of these are consequences of hormonal therapy against prostate cancer.

Keywords: Case report, Gastric neoplasms, Gastrointestinal endoscopy, Prostate-specific antigen, Prostatic neoplasms

\section{Background}

The prevalence of metastatic cancer to the stomach is low and ranges from $1.7 \%$ to $5.4 \%$ based on autopsy findings [1]. The most common sites of gastric metastasis are breast cancer, lung cancer, and malignant melanoma. Metastatic lesions are often more solitary than multiple occurrences and are frequently located on the greater curvature in the middle and upper third of the stomach. Endoscopically, a metastatic lesion is typically observed as a submucosal tumor with or without central

\footnotetext{
* Correspondence: cinagaki@cfs.med.osaka-u.ac.jp

${ }^{1}$ Department of Gastroenterology, Chiba Cancer Center, 666-2, Nitona-chou, Chuo-ku, Chiba-shi, Chiba 260-0801, Japan

${ }^{3}$ Department of Frontier Science for Cancer and Chemotherapy, Osaka University Graduate School of Medicine, E21-19, 2-2, Yamadaoka, Suita, Osaka 565-0871, Japan

Full list of author information is available at the end of the article
}

depression. However, some of these metastatic lesions resemble primary gastric cancer and histological confirmation, including that by immunohistochemistry, is indispensable for differential diagnosis [2].

In prostate cancer, metastases to bones and lymph nodes are common, but metastasis to the stomach is extremely rare [3]. Prostate cancer can occasionally present as a metastatic carcinoma with unknown primary origin; however, the origin of metastasis in such a setting is easily identified by using immunohistochemistry for prostate-specific antigen (PSA) and prostate-specific acid phosphatase (PSAP).

Here, we report a case of prostate cancer metastasis to the stomach, which resembled undifferentiated-type early gastric cancer (UD-EGC), as observed on both conventional and magnifying endoscopies. Endoscopic biopsy from the lesion was negative for PSA staining 
and was not useful for facilitating a correct diagnosis. Caution must be applied in interpreting endoscopy findings in patients with malignancies, particularly those under treatment.

\section{Case presentation}

The patient was a 75-year-old Japanese male who had prostate cancer with bone metastasis and high serum PSA level $(7040 \mathrm{ng} / \mathrm{ml}$, reference range $<4 \mathrm{ng} / \mathrm{dL})$ that responded well to luteinizing hormone-releasing hormone (LH-RH) agonist for 8 months. Abdominal CT scan revealed no evidence of prostate cancer progression. He was referred to our department due to a 4week history of epigastric discomfort. Physical examination was not remarkable. Laboratory work-up was not significant except for elevated ALP, LDH and PSA levels, which were improved compared to values before hormone therapy (Table 1).

Esophagogastroduodenoscopy (EGD) was performed and revealed a slightly depressed, discolored lesion with sharp margin against non-atrophic mucosa on the anterior wall of the middle gastric body (Fig. 1). Magnifying endoscopy (ME) with blue laser imaging (BLI) and linked color imaging (LCI) demonstrated a sparse and partially absent microsurface pattern with irregular microvessels in the depressed area. These findings are compatible with UD-EGC. Biopsy showed moderately differentiated adenocarcinoma and immunohistochemistry with PSA was negative. Contrasted computed

Table 1 Laboratory findings before hormone therapy (A) and at referral (B)

\begin{tabular}{llll}
\hline Laboratory Test & A & B & Normal Value \\
\hline $\mathrm{WBC}\left(\times 10^{9} / \mathrm{L}\right)$ & 8 & 6 & $3.3-8.6$ \\
$\mathrm{Hb}(\mathrm{g} / \mathrm{L})$ & $\mathbf{1 1 2}$ & $\mathbf{1 2 2}$ & $137-168$ \\
$\mathrm{Ht}(\%)$ & $\mathbf{3 3 . 6}$ & $\mathbf{3 6 . 9}$ & $40.7-50.1$ \\
$\mathrm{Plt}\left(\times 10^{9} / \mathrm{L}\right)$ & 227 & 183 & $158-348$ \\
$\mathrm{Alb}(\mathrm{g} / \mathrm{L})$ & $\mathbf{3 9}$ & 42 & $41-51$ \\
$\mathrm{Cre}(\mu \mathrm{mol} / \mathrm{L})$ & $\mathbf{4 5}$ & $\mathbf{5 3 . 9}$ & $57.4-62.7$ \\
$\mathrm{AST}(\mathrm{U} / \mathrm{L})$ & 18 & 27 & $13-30$ \\
$\mathrm{ALT}(\mathrm{U} / \mathrm{L})$ & 15 & 18 & $4-43$ \\
$\mathrm{LDH}(\mathrm{U} / \mathrm{L})$ & $\mathbf{1 1 2 3}$ & $\mathbf{2 7 6}$ & $124-222$ \\
$\mathrm{ALP}(\mathrm{U} / \mathrm{L})$ & $\mathbf{9 6 6}$ & $\mathbf{3 5 3}$ & $106-322$ \\
$\mathrm{Na}(\mathrm{mmol} / \mathrm{l})$ & 140 & 142 & $138-145$ \\
$\mathrm{~K}(\mathrm{mmol} / \mathrm{l})$ & 4.6 & 4.4 & $3.6-4.8$ \\
$\mathrm{Cl}(\mathrm{mmol} / \mathrm{l})$ & 108 & 104 & $101-108$ \\
$\mathrm{PSA}(\mathrm{ng} / \mathrm{ml})$ & $\mathbf{7 0 4 0}$ & $\mathbf{2 3 8}$ & $<4$ \\
\hline
\end{tabular}

Serum values of LDH, ALP and PSA values were decreased with hormonal treatment. Abnormal values are given in bold type

WBC white blood cell count, $\mathrm{Hb}$ hemoglobin, $\mathrm{Ht}$ hematocrit, Plt platelet count, Alb albumin, Cre creatinine, AST aspartate aminotransferase, ALT alanine aminotransferase, $L D H$ lactate dehydrogenase, $A L P$ alkaline phosphatase, $N a$ sodium, $K$ potassium, $C l$ chloride, $P S A$ prostate specific antigen tomography demonstrated absence of significantly enlarged perigastric lymph nodes and also there were no new sites of metastatic disease. Thus, we initially diagnosed it as a primary early gastric cancer. Considering his prostate cancer and estimated prognosis of several years, endoscopic submucosal dissection was performed. En bloc resection was successfully achieved without complication. Histopathologic findings from the resected specimen were remarkable for moderately to poorly differentiated adenocarcinoma, which predominantly existed in the superficial layer of the submucosa. Atrophy of the gastric fundic glands, which were replaced with fibrous tissue, were observed focally near the tumor infiltration site (Fig. 2). As metastasis was suspected, immunochemical staining was performed. The tumor was negative for PSA, cytokeratin (CK) 7, CK 20, and positive for PSAP (Fig. 3). Consequently, the lesion was finally confirmed as a metastatic gastric lesion of the prostate cancer.

At the time when the pathological diagnosis of the gastric metastases was made, patient's extragastric lesions were responding to endocrine therapy, and because of this we did not change his systemic treatment for prostate cancer.

\section{Discussion and conclusions}

Prostate cancer metastases to the stomach is very rare. As far as we know, there are only ten cases has been reported previously (Table 2). Most of the gastric metastases were detected at the primary staging or at the time of progression. Common endoscopic features were nodules with ulceration, folds thickening and multiple ulcerations. Notably, all previous cases were positive for PSA stain.

We initially failed to achieve the correct diagnosis because of two reasons. Features of both conventional and magnifying endoscopies of our case mimic those of UD$\mathrm{EGC}$, and biopsies from the gastric lesions were negative for PSA stain.

An endoscopic examination with conventional white light imaging (WLI) demonstrated a discolored and slightly depressed lesion with clear margin, which is recognized as the typical characteristic of UD-EGC and an uncommon manifestation of metastatic stomach lesions [4]. We presume that discoloration observed on WLI is related to histological improvement, which occurs in response to hormonal treatment. Histological changes, resulting from hormonal therapy for prostate cancer, include decreased number of cancer glands and increased periglandular collagenous stroma [5]. Therefore, we hypothesized the following mechanism of discoloration. Cancer infiltration resulted in atrophy of the fundic glands. Then, in response to hormonal therapy, malignant glands disappeared and were replaced with fibrous 


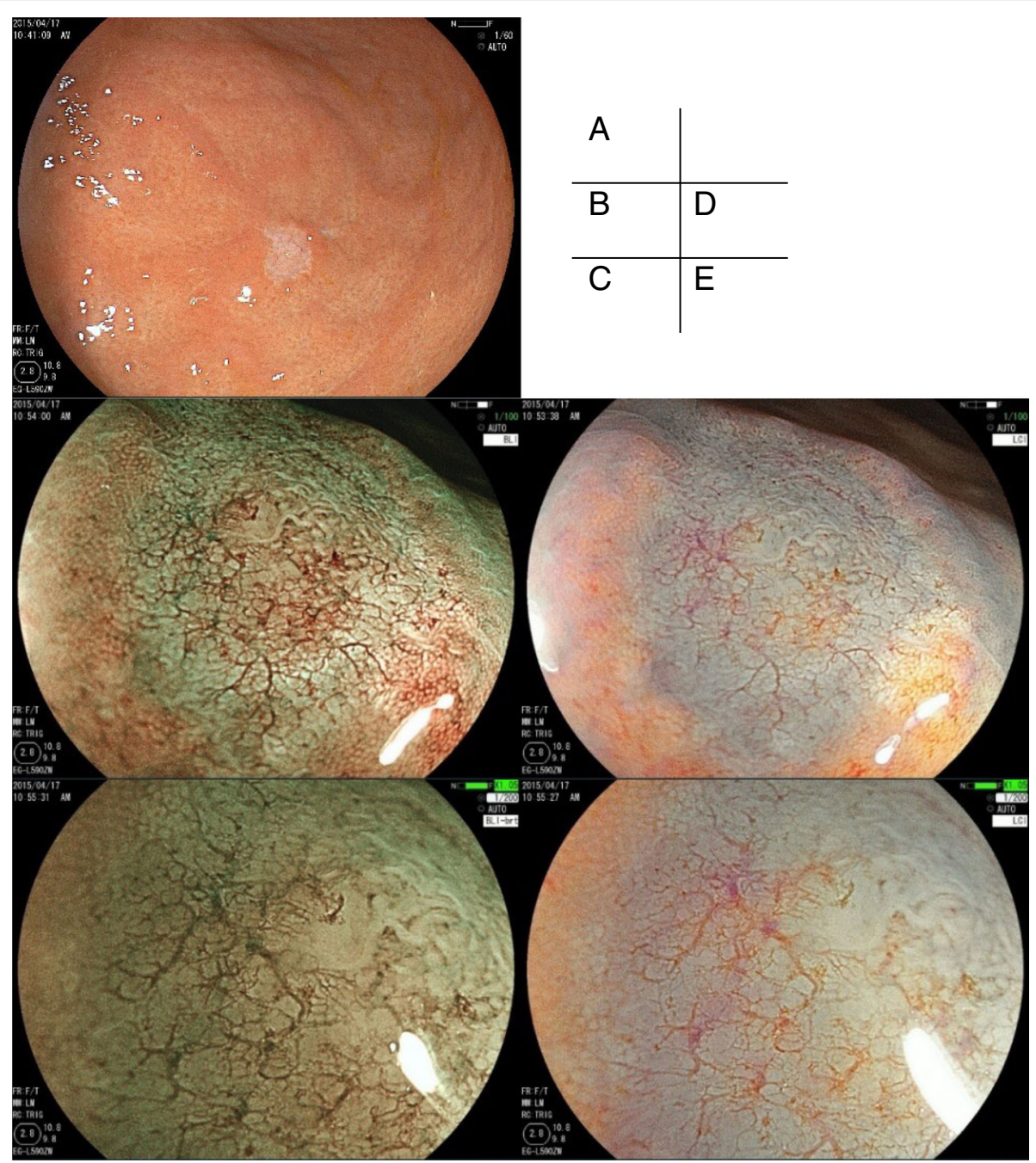

Fig. 1 Endoscopic Findings. a Conventional endoscopy with WLI. A slightly depressed, discolored lesion with sharp margin was observed against non-atrophic mucosa on the anterior wall of the middle gastric body. $\mathbf{b}$-e ME with BLI (b, c) and ME with LCl using indigo carmine dye spray (d, e). $\mathbf{c}$ and $\mathbf{e}$ are images with the highest power optical magnification. In the depressed area, microsurface pattern was sparse and partially absent. Microvascular pattern was irregularly irregular, that is, a variation in caliber, non-uniform shapes, and an asymmetric distribution. Both microsurface and microvascular patterns were indistinguishable from UD-EGC. WLI, white-light imaging; ME, magnifying endoscopy; BLI, Blue Laser Imaging; LCl, Linked Color Imaging; UD-EGC, undifferentiated early gastric cancer

tissue. Consequently, the mucous layer became scarce, giving rise to the discolored appearance on WLI.

Similar discoloration is observed in mucosa-associated lymphoid tissue (MALT) lymphoma at the site of tumor regression following Helicobacter pylori (H.pylori) eradication [6]. This change in color is considered to be due to a decreased number of gastric glands caused by neoplastic infiltration and elimination of lymphoid cell infiltration after $H$. pylori eradication. This histological change corresponds to our observation and may support our theory.

We also postulate that hormonal therapy contributed to the lesion's slightly depressed appearance. In primary gastrointestinal malignancies, flattening of elevated mucosa and ulceration are observed in response to chemotherapy [7]. Considering this, slight depression of the lesion may indicate a good response against hormonal therapy and is possibly preceded by more common endoscopic pattern, e.g., a bull's eye configuration.

On ME with BLI and LCI, we found a sparse microsurface pattern and an irregular microvessel pattern in the depressed area, which are nearly identical to those associated with UD-EGC $[4,8]$. BLI and LCI are novel technologies of image-enhanced endoscopy (IEE) and considered to possess good visibility as narrow-band imaging (NBI) [9]. The utility of magnifying IEE on metastatic lesions is not well studied. In our case, observation with ME suggested U-EGC. This might occur as a 


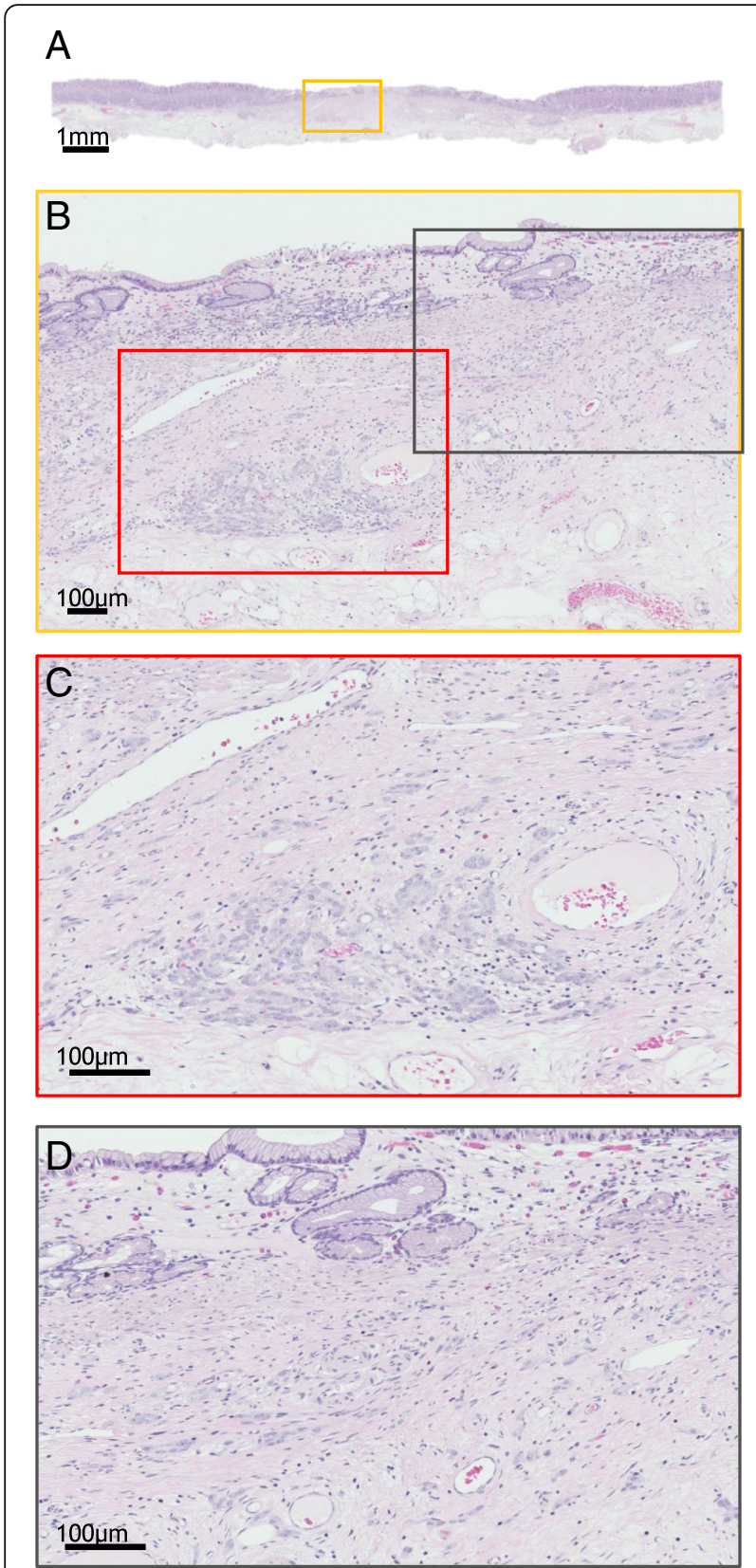

Fig. $2 \mathrm{H} \& \mathrm{E}$ staining of the resected specimen. a Panoramic view $(\times 1)$, b Low-magnification view $(\times 100)$ of the yellow frame in $A, \mathbf{c}$ High-magnification view $(\times 200)$ of the red frame in B, d Highmagnification view $(\times 200)$ of the gray frame in B. Histopathological findings revealed tumor cells, which mainly resided in the superficial submucosal layer, and also showed atrophy of the gastric fundic glands as well as increased stromal tissue. H\&E, hematoxylin and eosin

consequence of histological change following hormonal treatment.

By negative staining for PSA, we reached a false initial diagnosis of primary gastric cancer for this patient. Both PSA and PSAP are highly sensitive and specific immunohistochemical markers of prostate cancer [10], which are

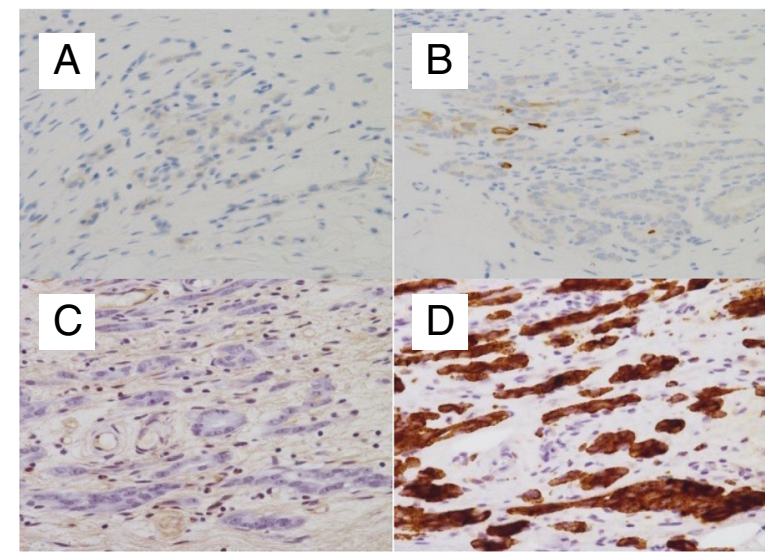

Fig. 3 Immunohistochemical staining of the resected specimen. The tumor was negative for CK7 (a), CK20 (b), and PSA (c) and was positive for PSAP (d). CK, cytokeratin; PSA, prostate-specific antigen; PSAP, prostate-specific acid phosphatase

Table 2 Summary of previous cases of gastric metastasis of prostate cancer

\begin{tabular}{|c|c|c|c|c|}
\hline Author & Age & $\begin{array}{l}\text { Treatment status } \\
\text { at the time of } \\
\text { gastric metastases }\end{array}$ & $\begin{array}{l}\text { Endoscopic } \\
\text { findings }\end{array}$ & IHC findings \\
\hline $\begin{array}{l}\text { Holderman } \\
\text { et al. [12] }\end{array}$ & 88 & Naiive & $\begin{array}{l}\text { Nodules with } \\
\text { central depression, } \\
\text { Folds thickening }\end{array}$ & $\begin{array}{l}\text { PSA (+), CK (+), } \\
\text { Mucin }(-)\end{array}$ \\
\hline $\begin{array}{l}\text { Christoph } \\
\text { et al. [13] }\end{array}$ & 67 & Naïve & N/A & PSA (+) \\
\hline $\begin{array}{l}\text { Hong et al. } \\
\text { [14] }\end{array}$ & 66 & $\begin{array}{l}\text { Disease } \\
\text { progression on } \\
\text { endocrine therapy }\end{array}$ & $\begin{array}{l}\text { Small elevations } \\
\text { with ulceration }\end{array}$ & PSA (+) \\
\hline $\begin{array}{l}\text { Onitilo } \\
\text { et al. [15] }\end{array}$ & 89 & Naïve & $\begin{array}{l}\text { Folds thickening } \\
\text { with dispensability, } \\
\text { Ulcerations }\end{array}$ & $\begin{array}{l}\text { PSA (+), CK (+), CG } \\
(-)\end{array}$ \\
\hline $\begin{array}{l}\text { Onitilo } \\
\text { et al. [15] }\end{array}$ & 57 & $\begin{array}{l}\text { Disease } \\
\text { progression on } \\
\text { endocrine therapy }\end{array}$ & $\begin{array}{l}\text { A broad based } \\
\text { ulcerated } \\
\text { exophytic lesion }\end{array}$ & $\begin{array}{l}\text { PSA (+), CK (+), CG } \\
(-)\end{array}$ \\
\hline $\begin{array}{l}\text { Bilici et al. } \\
\text { [16] }\end{array}$ & 69 & $\begin{array}{l}\text { Clinical remission } \\
\text { with endocrine } \\
\text { therapy }\end{array}$ & $\begin{array}{l}\text { Multiple } \\
\text { ulcerations }\end{array}$ & $\begin{array}{l}\operatorname{PSA}(+), \operatorname{PSAP}(+), \\
\operatorname{CK7}(-), \text { CK20 (-) }\end{array}$ \\
\hline $\begin{array}{l}\text { Mehrzad } \\
\text { et al. [17] }\end{array}$ & 71 & $\begin{array}{l}\text { Disease } \\
\text { progression on } \\
\text { chemotherapy }\end{array}$ & $\begin{array}{l}\text { A nodule with } \\
\text { ulceration }\end{array}$ & $\begin{array}{l}\text { CK AE1/AE3 }(+), \\
\text { PSA }(+), \text { CK7 }(-), \\
\text { CK20 }(-), \operatorname{CDX2}(-),\end{array}$ \\
\hline $\begin{array}{l}\text { Soe et al. } \\
\text { [18] }\end{array}$ & 64 & $\begin{array}{l}\text { Withdrawing } \\
\text { chemotherapy }\end{array}$ & Folds thickening & PSA (+), AMACR (+), \\
\hline $\begin{array}{l}\text { Patel et al. } \\
\text { [19] }\end{array}$ & 71 & $\begin{array}{l}\text { Status post surgery } \\
\text { and radiation } \\
\text { therapy }\end{array}$ & $\begin{array}{l}\text { A nodule, ulcer } \\
\text { and multiple } \\
\text { erosions }\end{array}$ & PSA (+) \\
\hline $\begin{array}{l}\text { Bhandari } \\
\text { et al. [20] }\end{array}$ & 58 & $\begin{array}{l}\text { Disease } \\
\text { progression on } \\
\text { endocrine therapy }\end{array}$ & $\begin{array}{l}\text { A nodule with } \\
\text { ulceration }\end{array}$ & $\begin{array}{l}\text { PSA (+), CK20 (+), } \\
\text { CK7 (-), }\end{array}$ \\
\hline This case & 75 & $\begin{array}{l}\text { Responding to } \\
\text { endocrine therapy }\end{array}$ & $\begin{array}{l}\text { Slightly depressed, } \\
\text { discolored lesion }\end{array}$ & $\begin{array}{l}\text { PSA }(-), \operatorname{PSAP}(+), \\
\text { CKT }(-), \text { CK20 (-), }\end{array}$ \\
\hline
\end{tabular}

IHC immunohistochemistry, (+) positive, (-) negative, CK cytokeratin, CG chromogranin, PSA prostate-specific antigen, PSAP prostate-specific alkaline phosphatase, AMACR alpha-methylacyl-coenzyme $A$ racemase 
useful for establishing the prostate origin of metastatic adenocarcinoma in diagnostic practice. However, PSA and PASA are less frequently expressed in small cell or poorly differentiated prostate carcinoma and pretreated carcinoma [5]. Unfortunately, we didn't perform biopsy of prostate. Considerably good response to hormone therapy is incompatible to clinical feature of prostate cancer associated with aggressive histology [11]. Therefore, we suppose negative staining for PSA in this case is likely due to hormonal therapy, whereas we cannot explain why reactivity to PSAP was maintained. We only used PSA staining prior to endoscopic resection because we did not suspect metastasis based on endoscopic findings. We might have avoided unnecessary endoscopic resection if we had included additional immunohistochemical stains, such as staining for PSAP on biopsy specimen, after considering the patient's history of treatment.

To our knowledge, we are the first to describe the case of prostate cancer metastasis to the stomach that was indistinguishable from UD-EGC. We suggest that the alterations in morphology and immunohistochemical staining owing to hormonal treatment made it a challenging diagnosis. Caution should be applied in interpreting endoscopic findings in patients with malignancies, particularly those undergoing treatment.

\section{Abbreviations \\ BLI: Blue laser imaging; CK: Cytokeratin; EGD: Esophagogastroduodenoscopy; H.pylori: Helicobacter pylori; IEE: Image-enhanced endoscopy; LCI: Linked color imaging; LH-RH: Luteinizing hormone-releasing hormone; MALT: Mucosa- associated lymphoid tissue; ME: Magnifying endoscopy; NBl: Narrow-band imaging; PSA: Prostate-specific antigen; PSAP: Prostate-specific acid phosphatase; UD-EGC: Undifferentiated-type early gastric cancer; WLI: White light imaging}

\section{Acknowledgements}

I would like to thank Dr. Hiroyuki Takeyama, Department of Pathology, and Dr. Makiko Itami, Head of Pathology for contributing images.

I am very grateful to all physicians, nursing staff, and other caregivers of the gastroenterology division at the Chiba Cancer Center.

\section{Funding}

The authors have no funding to report.

\section{Availability of data and materials}

All data analyzed during this study are included in this published article.

\section{Authors' contributions}

$\mathrm{Cl}, \mathrm{TS}, \mathrm{YK}$ and TH contributed to treatment of the patients. Cl wrote the manuscript. TS and TY reviewed the manuscript. All authors read and approved the final manuscript.

\section{Ethics approval and consent to participate}

This case report did not require the review by the Institutional Review Board of Chiba Cancer Center.

\section{Consent for publication}

Written informed consent was obtained from the patient for publication of the Case Report and any accompanying images.

\section{Competing interests}

The authors declare that they have no competing interests.

\section{Publisher's Note}

Springer Nature remains neutral with regard to jurisdictional claims in published maps and institutional affiliations.

\section{Author details}

'Department of Gastroenterology, Chiba Cancer Center, 666-2, Nitona-chou, Chuo-ku, Chiba-shi, Chiba 260-0801, Japan. ${ }^{2}$ Hara Clinic, 228-1, Haraoka, Tomiura-cyo, Minamibousou-shi, Chiba 299-2403, Japan. ${ }^{3}$ Department of Frontier Science for Cancer and Chemotherapy, Osaka University Graduate School of Medicine, E21-19, 2-2, Yamadaoka, Suita, Osaka 565-0871, Japan.

Received: 13 July 2016 Accepted: 31 July 2017

Published online: 07 August 2017

References

1. Oda, Kondo H, Yamao T, et al. Metastatic tumors to the stomach: analysis of 54 patients diagnosed at endoscopy and 347 autopsy cases. Endoscopy. 2001;33:507-10.

2. Kim GH, Ahn JY, Jung HY, et al. Clinical and endoscopic features of metastatic tumors in the stomach. Gut Liver. 2015;9:615-22.

3. Ono Y, Ozawa M, Suzuki K, et al. Autopsy findings of patients with urological neoplasms. Int J Clin Oncol. 2002;7:301-5.

4. Kanesaka T, Sekikawa A, Tsumura T, et al. Absent microsurface pattern is characteristic of early gastric cancer of undifferentiated type: magnifying endoscopy with narrow-band imaging. Gastrointest Endosc. 2014;80:1194-8.e1.

5. Petraki CD, Sfikas CP. Histopathological changes induced by therapies in the benign prostate and prostate adenocarcinoma. Histol Histopathol. 2007;22:107-18.

6. Urakami Y, Sano T, Begum S, Endo H, Kawamata H, Oki Y. Endoscopic characteristics of low-grade gastric mucosa-associated lymphoid tissue lymphoma after eradication of Helicobacter pylori. J Gastroenterol Hepatol. 2000;15:1113-9.

7. Japanese Gastric Cancer Association. Japanese classification of gastric carcinoma: 3rd English edition. Gastric Cancer. 2011;14:101-12.

8. Okada K, Fujisaki J, Kasuga A, et al. Diagnosis of undifferentiated type early gastric cancers by magnification endoscopy with narrow-band imaging. J Gastroenterol Hepatol. 2011;26:1262-9.

9. Fukuda H, Miura Y, Hayashi Y, et al. Linked color imaging technology facilitates early detection of flat gastric cancers. Clin J Gastroenterol. 2015;8:385-9.

10. Hameed O, Humphrey PA. Immunohistochemistry in diagnostic surgical pathology of the prostate. Semin Diagn Pathol. 2005;22:88-104.

11. Aparico AM, Harzstark AL, Corn PG, et al. Platinum-based chemotherapy for variant castrate-resistant prostate cancer. Clin Cancer Res. 2013;19:3621-30.

12. Holderman WH, Jacques JM, Blackstone MJ, Brasitus TA. Prostate cancer metastatic to the stomach. Clinical aspects and endoscopic diagnosis. J Clin Gastroenterol. 1992;14:251-4.

13. Christoph F, Grunbaum M, Wolkers F, Muller M, Miller K. Prostate cancer metastatic to the stomach. Urology. 2004;63:778.e14-5.

14. Hong KP, Lee SJ, Hong GS, Yoon H, Shim BS. Prostate cancer metastasis to the stomach. Korean J Urol. 2010;51:431-3.

15. Onitilo AA, Engel JM, Resnick JM. Prostate carcinoma metastatic to the stomach: report of two cases and review of the literature. Clin Med Res. 2010;8:18-21.

16. Bilici A, Dikilitas M, Eryilmaz OT, Bagli BS, Selcukbiricik F. Stomach metastasis in a patient with prostate cancer 4 years after the initial diagnosis: a case report and a literature review. Case Rep Oncol Med. 2012;2012:292140.

17. Mehrzad R, Agarwal A, Faller GT, Fiore JA. Prostate cancer metastasis to the stomach: 9 years after the initial diagnosis-case report and a literature review. J Gastrointest Cancer. 2014;45(Suppl 1):40-3.

18. Soe $A M$, Bordia $S$, Xiao $P Q$, et al. A rare presentation of metastasis of prostate adenocarcinoma to the stomach and rectum. J Gastric Cancer. 2014;14:271-4.

19. Patel H, Kumar A, Shaaban H, et al. Synchronous metastasis of prostate adenocarcinoma to the stomach and colon: a case report. N Am J Med Sci. 2014;6:152-4.

20. Bhandari V, Pant S. Carcinoma prostate with gastric metastasis: a rare case report. J Cancer Res Ther. 2015;11:659. 